\title{
Deposições de Óleo por Fêmeas de Centris analis (Fabricius) (Hymenoptera: Apidae: Centridini) Parasitadas por Physocephala spp. (Diptera: Conopidae)
}

\author{
Ricardo Marques Couto ${ }^{\bowtie}$ \& Evandro Camillo
}

Universidade de São Paulo, e-mail: rmcouto1@hotmail.com (Autor para correspondência ${ }^{\bowtie}$ ), ecamillo@ffclrp.usp.br.

\section{EntomoBrasilis 7 (2): 81-85 (2014)}

Resumo. O objetivo deste trabalho foi identificar comportamentos de deposição de óleo realizados pelas fêmeas da abelha solitária Centris analis (Fabricius), parasitadas por Physocephala spp. Esse estudo foi realizado no Campus de Ribeirão Preto da Universidade de São Paulo, Ribeirão Preto, seguindo a metodologia de ninhos-armadilha, nos quais as fêmeas construíram as células de cria em ninhos confeccionados com cartolina preta e introduzidos em blocos de madeira localizados em duas estantes na área de estudo. Das 26 fêmeas que nidificaram no local, 11 foram encontradas mortas dentro de ninhos-armadilha vazios. Depois foram levadas ao laboratório, juntamente com nove machos mortos, colocados em tubos de vidro e observados diariamente até a emergência do parasitoide Physocephala spp. (Diptera: Conopidae). Todos os ninhos construídos pelas fêmeas parasitadas receberam uma deposição extra de óleo sobre o fechamento da última célula de cria. Além disso, essas fêmeas permaneceram 5,4 dias no local depois de fecharem seus ninhos, realizando deposições extras de óleo sobre o fechamento de ninhos e fechando ninhos vazios $(\mathrm{n}=42)$, sem células de cria. Os dados deste trabalho sugerem que as deposições de óleo pelas abelhas parasitadas, aumentam as dificuldades de sucesso de ataque do parasitoide Leucospis cayennensis Westwood, visto que existem dois obstáculos para superar: óleo sobre a última célula de cria e óleo sobre o fechamento do ninho. É importante salientar que defendendo os ninhos contra tais invasores, as fêmeas parasitadas que realizaram deposições extras de óleo possibilitariam uma nova geração de conipídeos.

Palavras-Chave: Abelha solitária; Comportamento; Ninhos-armadilha.

\section{Oil Deposition by Females of Centris analis (Fabricius) (Hymenoptera: Apidae: Centridini) Parasitized by Physocephala spp. (Diptera: Conopidae)}

Abstract. The aim of this work was to identify behaviors of oil deposition by females of the solitary bee Centris analis (Fabricius) parasitized by Physocephala spp. This study was conducted at the Campus of the University of São Paulo, Ribeirão Preto, using trap-nests in which the females built the brood-cells in nests made with black cardboard, introduced in wood blocks that were placed on two shelves at site of study. From the 26 females that nested in the area, 11 were found dead inside the empty trap-nests. Next, they were taken to the laboratory together with nine dead males, placed in glass tubes and were observed daily until the parasitoid Physocephala spp. (Diptera: Conopidae) emerged. All nests built by the parasitized females had extra oil deposition on the last brood-cell occlusion. In addition, these females remained for 5.4 days at site of study after closing the nests, made extra oil depositions on the nest occlusions and closed 42 empty nests, without brood-cells. The data of this work suggest that the extra oil deposition by parasitized females, increase the difficulties to the success of the parasitoid Leucospis cayennensis Westwood, since there are 2 obstacles to be won: oil over the last partition and oil on the nest occlusion. It's good to point out that defending the nests against parasitoids the females would be ensuring a new generation of conopids.

Keywords: Behavior; Solitary bees; Trap-nests.

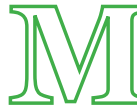
udanças na distribuição e nas atividades são os comportamentos mais comuns manipulados nos hospedeiros (Horton \& Moore 1993). Segundo SLANSKY JR. (1978), parasitoides têm desenvolvido mecanismos pelos quais a manipulação do comportamento hospedeiro garante proteção contra predadores.

O local da hibernação é crucial para a sobrevivência da pupa do parasitoide a qual deve suportar condições extremas de temperatura, desidratação, umidade, predadores e hiperparasitismo (BRodeur \& BoIvin 2004). Para proteger suas larvas, a vespa Hymenoepimecis argyraphaga Gauld (Hymenoptera: Ichneumonidae), manipula o comportamento do hospedeiro Plesiometa argyra Walckenaer (Aranea: Tetragnathidae), que aproximadamente há duas semanas antes de morrer, constrói um abrigo de proteção para a larva do parasitoide. Nessa mudança de comportamento, a aranha começa a tecer uma teia, suspensa no ar, que será importante para a metamorfose da larva e para proteção contra predadores terrestres (EBERHARD 2000).

Em contrapartida, Brodeur \& McNeIL (1989, 1992) defendem que o hospedeiro pode ser encontrado em microhabitats difíceis de serem atingidos, reduzindo assim, o risco de predação e hiperparasitismo. Hospedeiros parasitados podem mudar seus habitats, sendo encontrados em locais com altitudes mais elevadas (Stamp 1981; Brodeur \& McNeIL 1992).

Mudanças de comportamento foram observadas em abelhas Bombus terrestris (Linnaeus) (Apidae) parasitadas por conopídeos, que se enterram no solo antes de morrer, sugerindo que essas fêmeas se movem para locais mais protegidos em relação à queda de temperatura e desidratação, comuns durante a estação de inverno (MüLLER 1994). As moscas da família Conopidae são os mais importantes dípteros parasitoides de abelhas que atacam seu hospedeiro nos locais de forrageamento, depositando um ovo 
dentro de seu abdome (Pouvreau 1974). Devido ao ciclo de vida dos conopídeos, a larva tem que empupar e hibernar dentro do hospedeiro para completar seu desenvolvimento.

Muitos são os registros de associações entre os insetos do gênero Physocephala (Conopidae) e abelhas do gênero Anthidium, Anthophora, Eucera, Megachile, Halictus, Apis, Xylocopa, Bombus, Eulaema (Linsley 1958; HuRd 1978; Katayama \& MAETA 1998; SCHMid-Hempel 2001; OtTERSTATter et al. 2002; RASMUSSEN \& CAMERON 2004). As primeiras observações da associação entre as abelhas solitárias Centris analis (Fabricius) com espécies de Physocephala (Diptera: Conopidae) foram realizadas no Campus da Universidade de São Paulo, Ribeirão Preto, SP, onde fêmeas foram encontradas mortas dentro de ninhos-armadilha (SANTOS et al. 2008).

Segundo Schlindwein (2000) abelhas do gênero Centris apresentam um comportamento especializado para coletar óleo e são importantes polinizadores de numerosas espécies de plantas nas florestas neotropicais e no Cerrado, além de serem polinizadores efetivos de plantas de interesse comercial, como a aceroleira, Malpighia emarginata DC (OLIVEIRA \& SCHLINDWEIN 2003).

O óleo pode ser utilizado no alimento larval como substituto do néctar (VogEL 1990). Pode ser usado também como impermeabilizante das células de cria (NEFF \& Simpson 1981). Já, para Jesus \& GARÓFALO (2000), óleo e material vegetal são importantes para a construção das células de cria e para o fechamento do ninho. Ninhos completos apresentaram de 1 a 4 células arranjadas em série linear, usualmente seguidas por uma célula vestibular e o fechamento do ninho apresentou óleo como revestimento.

PEREIRA et al. (1999) sugerem que o revestimento do fechamento do ninho com óleo, confere proteção contra parasitoides que atacam ninhos já completados ou contra a usurpação de ninhos por fêmeas co-específicas. Em estudos realizados na Costa Rica com espécies de Centris, Vinson et al. (2006) sugeriram que a substância oleosa coletada pelas fêmeas não fora utilizada apenas para o aprovisionamento do ninho, mas também para a proteção do mesmo. Segundo estes autores, o óleo coletado de Byrsonima crassifolia (Linnaeus) apresentou ácido levulínico, o qual é considerado um importante fungicida.

Este trabalho mostra uma associação entre abelhas $C$. analis e o parasitoide Physocephala ssp. (Diptera: Conopidae). O objetivo é identificar nessas fêmeas parasitadas pelas moscas do gênero Physocephala comportamentos relacionados à deposição extra de óleo nos ninhos.

\section{MATERIAL E MÉTODOS}

O estudo foi realizado no Campus da Universidade de São Paulo, situado no município de Ribeirão Preto, SP, Brasil, seguindo a metodologia apresentada por SERRANo \& GARÓFALO (1978). Foram utilizados ninhos-armadilha confeccionados com cartolina preta, na forma de pequenos tubos (o,6 cm de diâmetro e $5,5 \mathrm{~cm}$ de comprimento) com uma das extremidades fechada com o mesmo material, e introduzidos em orifícios feitos em placas $(n=8)$ de madeira (55 ninhos-armadilha cada) $(5,0 \mathrm{~cm}$ de largura, $30,0 \mathrm{~cm}$ de comprimento e 12,0 cm de altura). As placas foram colocadas em prateleiras, sob coberturas (distantes $5 \mathrm{~m}$ ) construídas ao lado do laboratório de Ecologia do Departamento de Biologia da Faculdade de Filosofia Ciências e Letras de Ribeirão Preto-USP.

Durante o estudo, as fêmeas de $C$. analis que nidificaram no local foram coletadas, colocadas em frascos, e mantidas no gelo por um tempo aproximado de dois minutos. Após este período as abelhas foram marcadas ao longo do escutelo, mesoescuto, sutura escutoescutelar e tégulas com a utilização de canetas de marcação permanente Mitsubishi (Unipaint PX - 20). Indivíduos foram marcados com uma cor diferente para permitir a identificação no local de nidificação. Para isso, foi utilizado o código de cores sugerido pelo Prof. Sakagami, molhando a cabeça de um alfinete entomológico na tinta, testar a marcação na mão, e então marcar o tórax da abelha.

Para a obtenção dos dados sobre as deposições extras de óleo no fechamento da última célula de cria e no fechamento dos ninhos foram realizadas observações diárias que ocorreram entre 08:00 a 17:0oh. A diferença estatística em relação aos ninhos que receberam uma, duas, três ou quatro deposições extras de óleo em seus fechamentos foram analisados pelo teste de Qui-Quadrado $\left(\chi^{2}\right)$, do software Statistica 6, disponibilizado pelo laboratório do departamento.

As fêmeas e os machos de C. analis encontrados mortos dentro dos ninhos foram transferidos para tubos de vidro e levados ao laboratório, onde foram mantidos entre temperaturas de 21 a $29^{\circ} \mathrm{C}$ e observados diariamente, até as emergências dos adultos da mosca parasitoide Physocephala spp. (Diptera: Conopidae).

As espécies que emergiram foram mortas com acetato de etila e depositadas na coleção entomológica do Departamento de Biologia da Faculdade, Ciências e Letras de Ribeirão Preto, USP. Uma duplicata destas espécies está depositada na coleção entomológica do Museu Nacional, da Universidade Federal do Rio de Janeiro, RJ.

\section{RESULTADOS}

Associação entre C. analis e o parasitoide Physocephala spp.. Durante o estudo, 26 fêmeas foram previamente marcadas e 138 ninhos foram obtidos. Destas fêmeas, 11 foram localizadas mortas no interior de ninhos-armadilha vazios, juntamente com nove machos também encontrados mortos nos ninhos. Os insetos foram levados ao laboratório, dos quais emergiram 20 parasitoides após um período de 19 a 53 dias. Os parasitoides eram pertencentes a oito espécies: Physocephala soror Kröber (n = 2), Physocephala bipunctata Macquart $(\mathrm{n}=1)$, Physocephala inhabilis Walker $(\mathrm{n}=5)$, Physocephala rufithorax Kröber ( $\mathrm{n}=$ 5), Physocephala cayennensis Macquart $(\mathrm{n}=2)$, Physocephala aurifrons Walker $(\mathrm{n}=1)$, Physocephala bennetti Camras $(\mathrm{n}=1)$, Physocephala spheniformis Camras $(\mathrm{n}=3)$.

Comportamento de deposição de óleo no fechamento da última célula de cria. As 11 fêmeas de $C$. analis parasitadas construíram 37 ninhos com células de cria e 42 ninhos que foram apenas fechados (vazios), sem células de cria. Todos os ninhos com células de cria receberam uma deposição extra de óleo no fechamento da última partição celular (Figura 1), de maneira similar à deposição de óleo no fechamento dos ninhos (Figura 2).

Comportamentos de deposição extra de óleo em ninhos já fechados anteriormente. Outro comportamento observado ocorreu em relação ao tempo de permanência das fêmeas parasitadas no local de nidificação, após o fechamento de seus ninhos. Essas fêmeas permaneceram em média 5,4 dias realizando deposições extras de óleo $(n=134)$ em ninhos já fechados anteriormente, sendo que, 26 deposições extras $(19,4 \%)$ ocorreram quando as fêmeas depositaram óleo sobre seus próprios ninhos. Nas outras 108 deposições extras $(80,6 \%)$, o óleo foi colocado no fechamento de ninhos construídos por outras fêmeas.

Os depósitos referentes ao comportamento das fêmeas em colocar óleo em seus próprios ninhos foram significativamente menores que os depósitos realizados em ninhos construídos por outras fêmeas $\left(\chi^{2}=252 ; \mathrm{gl}=1 ; \mathrm{p}<0,05\right)$. Como exemplo dos comportamentos encontrados, observou-se que uma das fêmeas que nidificou no local construiu três ninhos com células de cria e depois de fechar seu último ninho com depósito de óleo, permaneceu mais cinco dias no local de nidificação realizando 18 depósitos extras de óleo sobre ninhos já fechados anteriormente, 


\section{A $\quad$ B}

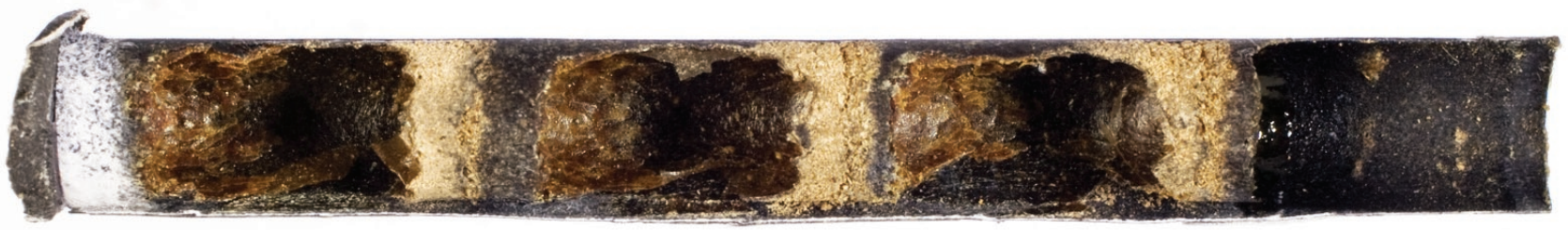

$2,3 \mathrm{~cm}$

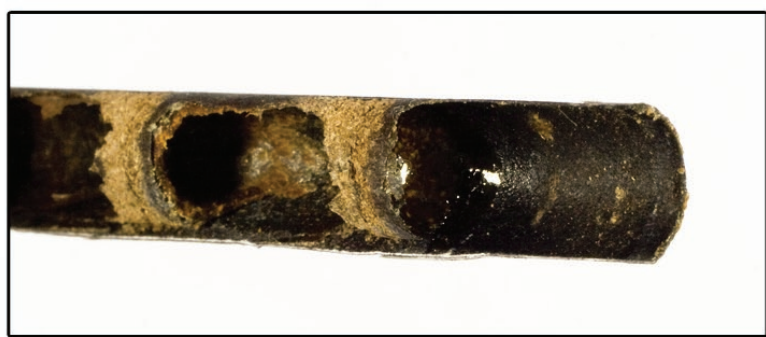

Figura 1. Ninhos de Centris analis com três células de cria (A, B, C) e uma célula vestibular (D) com óleo depositado sobre o fechamento da última célula de cria. Fonte: Ricardo Marques Couto

A

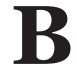

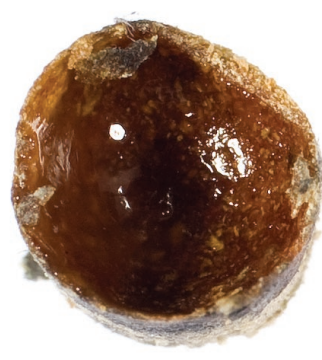

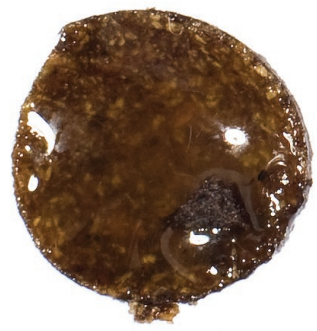

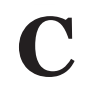

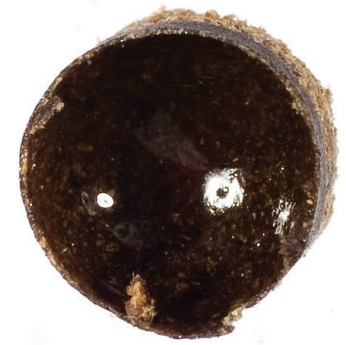

D

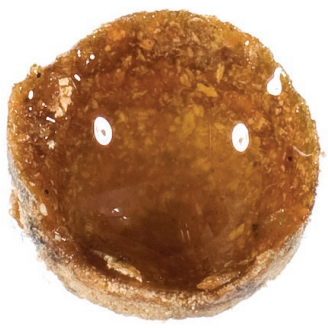

$1 \mathrm{~cm}$

Figura 2. Observação de óleo depositado sobre a última partição celular (A e C) de maneira similar ao óleo depositado sobre o fechamento do ninho (B e D).

sendo cinco sobre o fechamento de seus próprios ninhos e 13 em ninhos construídos por outras fêmeas. Essa fêmea também fechou seis ninhos vazios, sem células de crias.

Frequências de deposições extras em ninhos já fechados anteriormente. Dos 37 ninhos com células de cria construídos pelas fêmeas parasitadas, apenas $15(40,5 \%)$ receberam depósitos extras sobre o fechamento. No entanto, em ninhos construídos por outras fêmeas, os depósitos ocorreram em 77 ninhos, dos quais $53(68,8 \%)$ receberam apenas uma deposição extra, 18 $(23,4 \%)$ receberam duas deposições, cinco $(6,5 \%)$ receberam três deposições e apenas um ninho (1,3\%) recebeu quatro deposições de óleo (Tabela 1).

Tabela 1. Número de ninhos que receberam uma, duas, três e quatro deposições extras de óleo em seus fechamentos.

\begin{tabular}{|c|c|c|c|c|c|}
\hline \multirow[b]{2}{*}{ Comportamentos } & \multicolumn{5}{|c|}{ Número de ninhos que receberam de 1 a 4 deposições extras: } \\
\hline & $\begin{array}{c}1 \\
\text { deposição } \\
\text { extra }\end{array}$ & $\begin{array}{c}2 \\
\text { deposições } \\
\text { extras }\end{array}$ & $\begin{array}{c}3 \\
\text { deposições } \\
\text { extras }\end{array}$ & $\begin{array}{c}4 \\
\text { deposições } \\
\text { extras }\end{array}$ & $\begin{array}{c}\text { Total de } \\
\text { ninhos }\end{array}$ \\
\hline Deposições de óleo em seus próprios ninhos & 5 a & $9^{\mathrm{a}}$ & $1 b$ & - & 15 \\
\hline Deposições de óleo em ninhos construídos por outras fêmeas & $53 \mathrm{a}$ & $18 \mathrm{~b}$ & $5 \mathrm{c}$ & $1 \mathrm{c}$ & 77 \\
\hline Total de ninhos & $58 \mathrm{a}$ & $27 \mathrm{~b}$ & $6 \mathrm{c}$ & $1 \mathrm{~d}$ & 92 \\
\hline
\end{tabular}

*Valores seguidos por letras diferentes na mesma linha diferem estatisticamente. 


\section{DISCUSSÃO}

As fêmeas de $C$. analis $(\mathrm{n}=11)$ parasitadas pelo conopídeo foram encontradas mortas dentro de ninhos-armadilha em abrigo localizado no local de nidificação, protegido do sol e da chuva, sugerindo que as mesmas se moveram para um lugar seguro antes de morrerem. De acordo com Schmid-Hempel (1991), abelhas parasitadas do gênero Bombus quando estão perto da morte, se enterram no solo mais frequentemente que as abelhas não parasitadas, garantindo um local seguro para a hibernação da pupa. Este comportamento beneficia o parasitoide e não confere nenhum valor adaptativo ao hospedeiro.

Mudanças de atividades foram observadas em operárias de $B$. terrestris quando parasitadas por conopídeos, tais como: redução da atividade de forrageamento, alteração no padrão de coleta de pólen e mudança na preferência por flores para o forrageamento (Schmid-Hempel \& Schmid-Hempel 1990). Essas abelhas, quando parasitadas, tiveram preferência por temperaturas mais frias (Müller \& Schmid-Hempel 1993), além de apresentarem uma tendência em abandonar a colônia (SCHMid-Hempel \& MÜlLeR 1991, Müller \& SCHMid-Hempel 1993).

Neste trabalho foram observados em C. analis comportamentos de deposição de óleo no fechamento da última célula de cria, deposição de óleo em ninhos já fechados anteriormente e fechamento de ninhos vazios. Segundo Pereira et al. (1999) e JESUS \& Garófalo (2000), a substância oleosa no fechamento ou parede externa do fechamento dos ninhos de Centris confere maior proteção contra parasitoides e predadores que atacam ninhos já completados. GAZOLA \& GARóFALO (2003) observaram que em várias ocasiões, o parasitoide Leucospis cayennensis Westwood não obteve sucesso em romper a parede do fechamento do ninho de $C$. analis, provavelmente devido à substância oleosa ali depositada. VINSON \& FRANKIE (2000) reportaram que ninhos de Centris bicornuta Mocsary que não receberam óleo sobre a superfície de fechamento foram usurpados, e concluíram que a presença da substância oleosa é importante para reduzir a ação de coespecíficos em ninhos já completados. Além disso, os ninhos construídos podem apresentar células vazias situadas entre as células provisionadas (SAKAgAMI \& LAROCA 1971; WCISLO \& OROZCO 1993), as quais teoricamente reduziriam a taxa de parasitismo.

Os resultados deste trabalho sugerem que as deposições extras de óleo em ninhos já fechados anteriormente e sobre a última partição celular podem deixar os ninhos mais protegidos dos ataques do parasitoide $L$. cayennensis, porque a célula estaria duplamente protegida. Segundo Gazola \& Garófalo (2003), esse parasitoide apresenta duas táticas de ataques na entrada do ninho: a) ele introduz seu ovipositor através do "plug" de fechamento do ninho, até atingir a última partição celular. Neste caso, ele consegue mais facilmente atingir o interior da última célula, pois só o fechamento apresentaria a substância oleosa; b) o parasitoide rompe o "plug" de fechamento, entra no ninho, e caminha até atingir a parede da última partição celular. Portanto, se ela estiver revestida com óleo, as dificuldades para o parasitoide serão maiores.

Os dados também revelam que no comportamento de depositar óleo no fechamento de ninhos construídos por outras fêmeas, 53 ninhos $(68,8 \%)$ de um total de 77 receberam uma deposição extra de óleo, demonstrando que essas deposições foram bem distribuídas nos blocos de madeira contendo os ninhos-armadilha e apresentaram diferença significativa em relação aos ninhos que receberam duas, três e quatro deposições extras.

É importante salientar que ao defender os ninhos contra o parasitoide $L$. cayennensis, as fêmeas de $C$. analis asseguram uma nova geração para o conopídeo Physocephala spp. Assim, pode-se sugerir a ocorrência de uma competição entre os parasitoides, ou seja, o conopídeo estaria, por meio da fêmea hospedeira, assegurando mais substratos para ele, enquanto que $L$. cayennensis diminuiria o substrato a ser utilizado pelo conopídeo.

\section{AGRADECIMENTOS}

Ao Professor Doutor Carlos Alberto Garófalo, docente do Departamento de Biologia da Faculdade de Filosofia Ciências e Letras de Ribeirão Preto, da Universidade de São Paulo e a Professora Cátia Antunes Mello-Patiu, do Departamento de Entomologia, Museu Nacional, Universidade Federal do Rio de Janeiro.

\section{REFERÊNCIAS}

Brodeur, J. \& J.N. McNeil, 1989. Seasonal microhabitat selection by an endoparasitoid through adaptive modification of host behaviour. Science, 244: 226-228.

Brodeur, J. \& J.N. McNeil, 1992. Host behaviour modification by the endoparasitoid Aphidius nigripes: a strategy to reduce hyperparasitism. Ecological Entomology 17: 97-144.

Brodeur, J. \& G. Boivin, 2004. Functional ecology of immature parasitoids. Annual Review of Entomology, 49: 27-49.

Eberhard, W.G., 2000. Spider manipulation by a wasp larva. Nature, 406: 255-256.

Gazola,A.N.\&C.A. Garófalo, 2003. Parasitic behavior of Leucospis cayennensis Westwood (Hymenoptera, Leucospidae) and rates of parasitism in populations of Centris (Heterocentris) analis (Fabricius 1804) (Hymenoptera: Apidae: Centridini). Journal of the Kansas Entomological Society, 76: 131-142.

Horton, D.R. \& J. Moore, 1993. Behavioral Effects of Parasites and Pathogens in Insect Hosts, p. 107-124. In: Beckage, N.E., S.N., Thompson, \& B.A., Federici (Eds). Parasites and Pathogens of Insects. San Diego, Academic Press, 294p.

Hurd, P.D., 1978. An annotated catalog of the carpenter bees (genus Xylocopa Latreille) of the Western Hemisphere. Washington. Smithsonian Institution Press, 106p.

Katayama, E. \& Y. Maeta, 1998. The fourth host of Physocephala obscura Kröber found in Japan (Diptera, Conopidae). Chugoku Kontyu, 12: 23.

Jesus, B.M.V. \& C.A. Garófalo, 200o. Nesting behavior of Centris analis in southeastern Brazil (Hymenoptera, Apidae, Centridini). Apidologie, 31: 503-515.

Linsley, E.G., 1958. The ecology of solitary bees. Hilgardia, 27: 543-599.

Müller, C.B. \& P. Schmid-Hempel, 1993. Exploitation of cold temperature as defense against parasitoids in bumblebees. Nature, 363: 65-67.

Müller, C.B., 1994. Parasite-induced digging behaviour in bumble bee workers. Animal Behavior, 48: 961-966.

Neff, J.L. \& B.B. Simpson, 1981. Oil-collecting structures in the Anthophoridae (Hymenoptera): morphology, function, and use in systematics. Journal of the Kansas Entomological Society, 54: 95-123.

Oliveira, M. D. \& C. Schlindwein, 2003. Espécies de Centris e Epicharis (Apidae, Centridini) como polinizadores de Malpighia emarginata (acerola - Malpighiaceae) na Zona da Mata em Pernambuco. In: VI Congresso de Ecologia do Brasil. Anais de Trabalhos Completos. Simpósios Biodiversidade, Unidades de Conservação, Indicadores Ambientais, Caatinga, Cerrado. Fortaleza: Editora da Universidade Federal do Ceará. p. 224-225.

Otterstatter, M.C., T.L. Whidden \& R.E. Owen, 2002. Contrasting frequencies of parasitism and host mortality among phorid and conopid parasitoids of bumble-bees. Ecological Entomology, 27: 229-237.

Pereira, M., C.A. Garófalo, E. Camillo \& J.C. Serrano, 1999. Nesting biology of Centris (Hemisiella) vittata Lepeletier in southeastern Brazil (Hymenoptera, Apidae, Centridini). Apidologie, 30: 327-338.

Pouvreau, A., 1974. Les enemies des bourdons. II. Organismes affectant les adultes. Apidologie, 5: 39-62.

Rasmussen, C. \& S.A. Cameron, 2004. Conopid fly (Diptera: 
Conopidae) attacking large orchid bees (Hymenoptera: Apidae: Eulaema). Journal of the Kansas Entomological Society, 77: 61-62.

Sakagami, S.F. \& S. Laroca, 1971. Observations on the bionomics of some neotropical xylocopine bees with comparative and biofaunistic notes (Hymenoptera, Anthophoridae). Journal of the Faculty of Science, Series VI, Zoology, 18: 57-127.

Santos, A.M., J.C. Serrano, R.M. Couto, L.S.G. Rocha, C.A. Mello-Patiu \& C.A. Garófalo, 2008. Conopid Flies (Diptera: Conopidae) Parasitizing Centris (Heterocentris) analis (Fabricius) (Hymenoptera:Apidae:Centridini). Neotropical Entomology, 37: 606-608.

Schlindwein, C., 2000. A importância de abelhas especializadas na polinização de plantas nativas e conservação do meio ambiente. Anais do Encontro sobre Abelhas 4: 131-141.

Schmid-Hempel, P. \& R. Schmid-Hempel, 1990. Endoparasitic larvae of conopid flies alter pollination behaviour of bumblebees. Naturwissenschaften, 27: 50-52.

Schmid-Hempel, P., 1991. The ergonomics of worker behavior in social hymenoptera: I. Some preliminaries. Advances in the Study of Behavior, 20: 87-134.

Schmid-Hempel, R. \& C.B. Müller, 1991. Do parasitized bumblebees forage for their colony? Animal Behaviour, 41: 910-912.

Schmid-Hempel, P., 2001. On the evolutionary ecology of hostparasite interactions: addressing the question with regard to bumblebees and their parasites. Naturwissenschaften, 88: 147-158.

Serrano, J.C. \& C.A. Garófalo, 1978. Utilização de ninhos artificiais para o estudo bionômico de abelhas e vespas solitárias. Ciência e Cultura, 30: 597-598.
Slansky Jr, F., 1978. Utilization of energy and nitrogen by larvae of the imported cabbageworm, Pieris rapae, as affected by parasitism by Apanteles glomeratus. Environmental Entomology, 7: 179-185.

Stamp, N.E., 1981. Behavior of parasitized aposematic caterpillars: advantageous to the parasitoid or the host? American Naturalist, 118: 715-725.

Vinson, S.B. \& G.W. Frankie, 2000. Nest Selection, usurpation, and a function for the nest entrance plug of Centris bicornuta (Hymeoptera: Apidae). Annals of the Entomological Society of America, 93: 254-260.

Vinson, S. B., G.W. Frankie \& H.J. Williams, 2006. Nest liquid resources of several cavity nesting bees in the genus Centris and the identification of preservative, levulinic acid. Journal of Chemical Ecology, 32: 2013-2021.

Vogel, S., 1990. History of the Malpighiaceae in the light of pollination ecology. Memoirs of the New York Botanical Garden 55: 130-142.

Wcislo, W.T., A. Wille \& E. Orozco, 1993. Nesting biology of tropical solitary and social sweat bees, Lasioglossum (Dialictus) figueresi Wcislo and L. (D.) aeneiventri (Friese) (Hymenoptera:Halictidae). Insectes Sociaux, 40: 21-40.

\section{Recebido em: $08 / 08 / 2013$}

Aceito em: 06/o3/2014

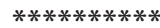

\section{Como citar este artigo:}

Couto, R.M. \& E. Camillo, 2014. Deposições de óleo por fêmeas de Centris analis (Fabricius) (Hymenoptera: Apidae: Centridini) parasitadas por Physocephala spp. (Diptera: Conopidae). EntomoBrasilis, 7 (2): 81-85.

Acessível em: doi:10.12741/ebrasilis.v7i2.382
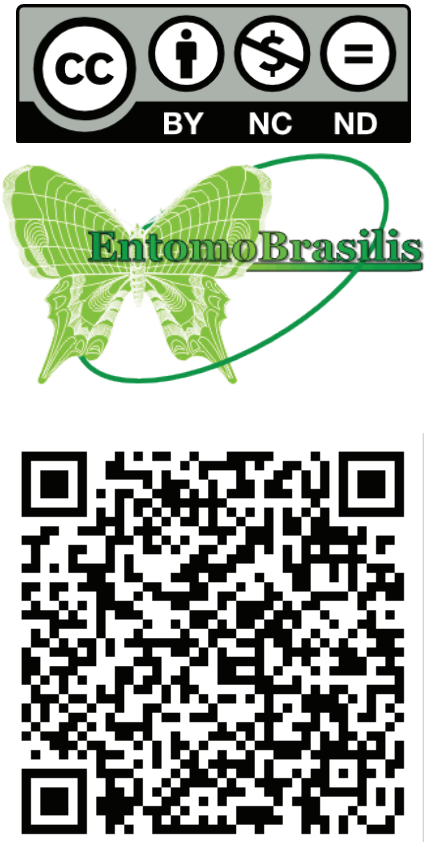